\title{
Euskal kanta bat 1783ko antzerki-lan batean A Basque song in a 1783 play
}

\author{
Eneko Zuloaga \\ Euskal Herriko Unibertsitatea UPV/EHU
}

\begin{abstract}
In this paper I present a critical edition of a short song written in Basque. It is a well known comic piece that continues to be sung even nowadays, and it was inserted by Rita Barnetxea in one of her dramas (Catalin, 1783). Some of the features attested in it are quite interesting from the linguistic point of view. In short, the text combines modern traits with several archaisms which were more common 200 or 250 years earlier than in the end of the 18th century. On the one hand, this paper intends to fix a critical version of the text. On the other hand, an exhaustive analysis of the innovations (graphic distinctions and phonological rules) and the archaisms (morphosyntactic features and lexical variants) is given in order to highlight the peculiarity of the text.
\end{abstract}

Keywords: Western Basque, Rita Barnetxea, folk literature, critical edition, 18th century, multilingualism.

\section{Laburpena}

Lan honetan euskaraz idatzitako euskal kanta labur baten edizio kritikoa aurkezten dut. Pieza umoretsua eta ezaguna da, gaur egun ere kantatzen dena, eta Rita Barnetxeak bere antzerki-lanetako batean (Catalin, 1783) txertatu zuen. Bada, kantuak biltzen dituen zenbait ezaugarri interesgarri askoak dira hizkuntzaren ikuspegitik. Labur azalduta, testuan nahasturik ageri dira zenbait erabilera moderno eta ez 18. mendearen amaieran baina 200 edo 250 urte lehenago arrunt ziren arkaismo batzuk. Alde batetik, lan honek testuaren bertsio kritikoa finkatu nahi du. Beste alde batetik, berrikuntzen (bereizketa grafikoak eta arau fonologikoak) eta arkaismoen (ezaugarri morfosintaktikoak eta aldaera lexikoak) azterketa zehatza ematen da, testuaren berezitasuna nabarmentzeko.

Hitz gakoak: Mendebaleko euskara, Rita Barnetxea, literatura herrikoia, edizio kritikoa, 18. mendea, eleaniztasuna. 


\section{Sarrera*}

Ezagun da emakume idazleei tradizioz eta oraintsu arte ez zaiela leku handirik egin ez tokian tokiko literaturetan, ez literatura horien historietan. Rita Barnetxea ${ }^{1}$ bilbotarra bizi izan zen sasoian ere gutxi ziren emakume idazle ezagunak hala Euskal Herrian nola Espainian. Palacios Fernándezek dioenez, «A pesar de que encontramos en tiempos pasados algunas mujeres que alcanzaron un lugar destacado en las letras españolas, su presencia es meramente testimonial. Tenían vedada cualquier osadía intelectual; la simple afición a la lectura podía atraerle la acusación de "bachillera"» (2000: 83). xviII. mendeko kultura-gizon batzuek emakumeen lanak aldarrikatu arren, eta emakume batzuen lorpen intelektualak lorpen, ez dirudi Barnetxeak itzalpetik irtetea lortu zutenik: Inmaculada Urzainquiren arabera, dozena erdi emakume antzerkigile besterik ez zeuden Barnetxea baino lehen (2006: XVIII); Palacios Fernándezen arabera (2000: 87), ordea, ehun bat izan ziren XviII. mendean, nahiz eta gehienen lanak argitaratu gabe geratu ziren. Ez du ematen lan horiek hemen aipatuko ditugun noblezia-giroko bilera pribatuetatik irten zirenik.

xviII. mendeko emakume baten testua dakargu lan honetan; zehazki, Rita Barnetxearen Catalin (1763) antzerki-lanean ageri den euskal kanta laburra: lau lerro besterik ez ditu kantak, baina ezin interesgarriagoa da bai alderdi filologikotik, bai linguistikotik. Azken hamar urteotan birritan argitaratu den arren (ez beti behar bezain ondo), guk geuk oraintsu izan dugu kantaren berri, eta, aparteko edizioa eta iruzkina merezi zituela iritzita, hona dakartzagu biak.

Mitxelenak zioenez, «No se debe olvidar, por otra parte, que nuestros textos son de inestimable valor por lo menos para el historiador de la lengua. En este caso, como ocurre con cualquier mercancía, su misma escasez basta para aumentar el precio» (1961a: 57). Horren erakusgarri da Barnetxearen laneko kanta, lau lerrotan hainbat aztergai interesgarri baititu: grafia, grafiak islatzen duenaren interpretazioa, XVIII. mendearen amaierarako ezohiko arkaikotasun morfosintaktikoa... Oso testu interesgarria da, eta Mitxelenaren esana berretsiz gogorarazten digu, bere laburtasunean, zenbat dugun oraindik ere hausnartzeko, ikasteko eta argitzeko hala euskararen historiaz nola historia hori hezurmamitzen duten materialez.

\section{Rita Barnetxea: bizitza-zertzeladak eta Catalin antzerki-lana}

\subsection{Bizitza-zertzeladak}

Bizkaiko Elizaren Histori Arkibuan gordetako bataio-agiriaren arabera, Maria Rita Nicolasa Petra Barnechea Morante de la Madrid, José Fernando de Barnechea Nobia y Barcoren (Portuko II. markesa) eta Ana María Morante de la Madrid Caste-

* Lan honek MINECOk finantzatutako «Monumenta Linguae Vasconum (V): periodización y cronología» (kodea: FFI2016-76032-P) taldearen babesa izan du. Bihoazkie nire eskerrak taldekideei, testua lehenengoz aurkeztean iradokitakoengatik, eta, bereziki, Gidor Bilbao eta Joseba A. Lakarrari, lan honen akuilari izateagatik; orobat Borja Ariztimuńori, aurreko bertsioa irakurtzeko beta hartzeagatik.

${ }^{1}$ Egileaz orain arte egin diren azterlanetan «Barrenetxea» aipatu izan da, baina bataio-agirian argi ageri da «Barnechea» aitaren zein alabaren abizena aipatzean. Bataio-agiri hori Bizkaiko Elizaren Histori Arkibuan aurki daiteke. Erreferentzia-zenbakia: ES/AHEB-BEHA/F006.080. Signatura: 0683/001-00. 
jonen (La Solanako markesa) alaba, 1757ko maiatzaren 13an jaio zen Bilboko Alde Zaharrean. Gazterik utzi zuen Bizkaiko hiriburua: 1761ean ama hil ondoren, aita apaiz sartu zen, Santiago apostoluaren botoen diputatu eta administratzaile izendatu zuten, eta familia Valladolidera joan zen. Han, Las Huelgasko monasterioan ikasi zuen Rita Barnetxeak, 1775eko urtarrilaren 3an Juan de Sahagún de la Mata Linaresekin (Carpioko kondea eta Calatravako zalduna) ezkondu zen, eta Bartzelonara abiatu ziren, lan-kontuak tarteko. Bi alaba (María Martina eta Francisca Javiera) erditu ondoren, 1780an, Barnetxearen senarra Erregearen Jauregiko Barrutiko Alkateen Salako kide izendatu zuten, eta Madrila joan ziren: Espainiako hiriburuan hil zen Rita Barnetxea 1795eko azaroaren 23an.

Gurasoen eta senarraren noblezia-tituluek islatzen dute hizpide dugun egilea gizartearen goi-mailan jaio eta bizi izan zela. Sasoi hartako harremanei dagokienez, badakigu XVIII. mendearen azken hamarkadetan Madrilgo goi-mailako zirkuluetan zebilela; besteak beste, Albako dukesaren inguruan ibili zen, eta Jovellanos asturiarrak estimutan zituen Sahagún de La Mata eta Barnetxea senar-emazteak (Urzainqui 2006: XxiI). Bestalde, 1787an Madrilen «Junta de Damas de Honor y Mérito» sortu zenean, batzorde hartako kide izendatu zuten. Euskal Herriari gagozkiolarik, sorterria txikitarik utzi zuen arren, izan zuen harremanik gerora ere Bilbo inguruarekin, hainbat bidaia egin baitzituen Euskal Herrira (Urzainqui 2006: xxxviII). 1768an sortutako Euskalerriaren Adiskideen Elkartea ere hurbiletik ezagutu zuen: aita, senarra, aitaginarreba, koinatua eta alaba baten aitaginarreba elkartekide izan ziren.

Barnetxea osasun ahulekoa omen zen, baina badirudi etxekoen eta adiskideen artean bere zaletasunak patxadaz eta modu atseginean ikasteko eta lantzeko giro aproposa zuela: bere senarra ere gizon irakurria zen, eta halako giroetan ohikoa zen adiskide eta lagunak etxera gonbidatzea, arratsalde-pasa: karta-jokoan aritzeko ez ezik, honetaz eta hartaz, ikuskizunez, irakurritakoez eta idatzitakoez jarduteko aukera bikainak ere baziren, bai eta bilerakideek prestatutako antzerki-piezak jendaurrean azaltzeko bilera aproposak ere. ${ }^{2}$

\subsection{Catalin antzerki-lana}

\subsubsection{Lanaren testuinguruaz}

Rita Barnetxearen bi antzerki-lan iritsi zaizkigu (hemen hizpide izango dugun $\mathrm{Ca}$ talin eta La aya izeneko komedia), ${ }^{3}$ baina badakigu besterik ere idatzi zuela: izenbururik gabeko beste komedia bat, Mantxatik bidaia egin ahala edo egin ondoren idatzitako kronika, zenbait poema liriko eta beste komedia-lan batzuk sortzeko oharrak

2 J. Towsend-ek deskribatu zuen etxeko bilera haietako giroa: «En la [casa] del conde de Carpio, todos, a excepción de un italiano, eran españoles, y la diversión habitual, un juego de cartas. Cerraba allí la velada una cena ligera. El conde llegaba antes de las diez, y cuando no iba al teatro pasaba la tarde con su familia. Él es un hombre culto y sensible, y ella puede animar cualquier reunión con su sola presencia» (1988: 210).

3 Comedia en prosa intitulada "La Aya». En un acto da izenburu osoa. Galdutzat jotzen zen, harik eta María Jesús García Garrosak (Valladolideko Unibertsitatea) Madrilgo Biblioteka Nazionalean kopia bat aurkitu zuen arte. Horretaz eta Espainiako komedia neoklasikoaren esparruan Rita Barnetxeak egindako aitzindari-bideaz, begiratu García Garrosa (2005) lana. 
(tartean, haurrentzat prestaturiko komedia bat). Egilea hil ondoren sakabanatu egin ziren familiaren agiriak, eta horrek zaildu egiten du lan horiek eta idatzita utz zitzakeen beste batzuk aurkitzea.

Gure ezagutzatik eta lan honen helburuetatik harago geratzen da Espainiako XVIII. mendeko antzerkigintza, baina esan dezagun, Urzainquiren azterlanari jarraikiz, Catalin lan neoklasikoa dela, berritzailea, nahiz eta obra xumea izan (2006: XxxI eta hurrengoak). Komedia sentimental neoklasikoa da, non proposamen etikoak eta ikuspegi ilustratua azaltzen baitira (xLIv). Portugalete aldeko baserri-giroan kokatu zituen egileak gertakizunak, eta, gerora ere aipatuko dugunez, Barnetxeak berak ezagutu bide zuen giro euskalduna sortzeko baliatu zituen hona dakarkigun kanta eta beste elementu batzuk (toponimia eta antroponimia, kasurako).

Halako lan bat taxutu izanak islatzen du egilea irakurria zela, bazuela lehenagoko idazleen eta idazle garaikideen literatura dramatikoaren berri; orobat, Adiskideen Elkartekoen eragina ikusten du Urzainquik bilbotarraren ikuspegi berritzailean: ezagun da antzerkiak leku nabarmena zuela elkartekideen biltzarretan, eta elkartea bera erreformatzailea eta klasizista zela (2006: XxxIII). Altzibarrek dioenez, «Lehen urte hauetan Elkarteak, esan nahi baita noblezia ilustratuak, garrantzi handia eman zion antzerkiari denborapasa eta irakaskuntz baliabide gisa” (1991: 35). Antzerki-moldeari dagokionez, El borracho burladoz ari dela, Altzibar bat dator Urzainquirekin: «Herria eraberritu eta eraldatzearen bidetik antzerkia ere aldatu nahi izan zuten [Adiskideen Elkarteko kideek] (...) Teatro neoklasikoaren oinarrizko printzipioari datxezkio, irakaste xedeari alegia, eta onartu egiten dituzte arautegi neoklasikoa eta hiru unitateen araua, oso hertsiki ez bada ere» (36). Izpiritu horretatik edan bide zuen, beraz, Barnetxeak.

\subsubsection{Catalin: $1783 k$ argitalpena}

Catalin lanaren edizioa ona da, zaindua eta paper onean inprimatua, baina ematen du klandestinoa dela: egilearen baimenik gabe kaleratu duela dio argitaratzaileak hitzaurrean. Lanaren azalean ez da ematen ez egilearen, ez inprimatzailearen izenik. Catalin izenburua, «Comedia en prosa» zehaztapena, Andrés Rey Artieda-ren aipu labur bat, ${ }^{4}$ argitalpenaren lekua (Jaen) eta data (MDCCLXXXIII) besterik ez dira ageri (ikusi 1. irudia eranskinetan): 5 Urzainquiren arabera, bitxia da obra Jaenen agertu izana, hiriak ez baitzuen inprenta-tradiziorik (2006: XxxIv).

Ematen du argitaratzaileak Barnetxearen hurrekoa izan behar zuela, bilbotarraren izaera eta beste lan batzuk aipatu baitzituen:

Disculpará tambien la licencia, con que aun sin noticia de su Autora, me atrevo á producirla, como parto feliz de el singular talento que la ha concedido la Naturaleza. No es esta la primera, ni la unica obra, en que lo ha acreditado suficientemente

4 «Es la Comedia espejo de la vida, / su fin mostrar los vicios, y virtudes / para vivir con òrden, y medida».

5 Ez dirudi, halere, egiletasunaren inguruko zalantzarik dagoenik: Vicente García de la Huertak bilbotarrari egotzi zion Theatro Hespañol lanean (1786) - Juana Inés de la Cruz eta Rita Barnetxea dira lan horretan ageri diren emakume bakarrak-, Serrano y Sanzek eskuizkribua ikusi omen zuen Barnetxearen testuen artean eta beste katalogo batzuetan ere hala ageri da. 
antes de aora, y sinó fuera por temor de ofender su suma modestia, y moderacion, me detendría a referirlas; pero baste la presente, que en medio de una muy quebrantada salud compuso para diversion, y recreo de su animo tranquilo siempre, aun en medio de sus mayores indisposiciones, é incomodidades corporales. Ella, á la verdad, dá una suficiente idéa de el noble espiritu de su Compositora, y obliga al Lector á tomar cierto interés en su salud, y á desear, que Dios se la conceda con mayor robustéz muchos, y dilatados años, para lustre de las Letras, y honor de las de su Sexo. (1783: 4-6)

Horiek jakinik, pentsa liteke Catalin Barnetxearen konplizitatearekin argitaratu zuela bilbotarraren adiskideren batek; zehazki, Ignacio Luis de Agirre aipatzen du Urzainquik: Adiskideen Elkarteko bazkidea zen, Barnetxearen senarraren laguna, eta denboraldi bat emana zuen Andaluzia aldean (2006: xx).

\section{Testua $^{6}$}

\subsection{Beste transkripzio batzuk}

XVIII. mendeko argitalpenaz geroztik, Barnetxearen komediako euskal testua behin baino gehiagotan transkribatu da, batez ere azken urteotan: aipatzekoak dira Palacios Fernándezen ${ }^{7}$ eta Urzainquiren transkripzioak, bestelako artikulu eta lan laburrago batzuetako aipuetan erabili izan direnak.

Lehenengoaz denaz bezainbatean, badira zuzendu beharreko zenbait forma, betiere Palacios Fernándezek guk ezagutzen ez dugun edizioren bat (testua beste modu batera ematen duena) erabili ez bazuen: acsobac ematen du, 1783ko testuak acsohac 'atsoak' dioen lekuan; lau aldiz dakar acsó 'atzo' bigarren lerroan, jatorrizkoan bost aldiz agertu arren; amaierako dila 'dadila' laguntzailean tileta ezarri dio azken bokalari, nahiz eta jatorrizkoan halakorik egon ez. Bestalde, Palacios Fernándezen 2002ko liburua iruzkintzen ari zela, Henrike Knörrek arestikoaren bertsioa kopiatu zuen, eta $<\mathrm{k}>$ batek ihes egin zion, acsorik baitakar (2005: 72). ${ }^{8}$ Urzainquiren ediziora etorrita, transkripzioa berbaz berbakoa da, ezelako aldaketarik gabea, eta jatorrizko testuaz gain, erdal itzulpena eta euskara gaurkotuko bertsioa ere ematen du.

\subsection{Gure edizioa}

Lehenago aipatu bezala, kanta bigarren eszenan (8. eta 9. orrialdeak) dago eta laburra da. Euskal testua agertzen den testuingurua hobeto kokatze aldera, aurretik duen erdal pasartea ere ekarri dugu hona. Gaztelaniazko zati horretan azentu grafikoen eta puntuazio-zeinuen erabilera besterik ez dugu eguneratu.

${ }^{6}$ Ikusi kantaren faksimilea lan honen eranskinetan (2. eta 3. irudiak).

7 «Noticia sobre el parnaso dramático femenino en el siglo xviII» (2000) artikuluan eta La mujer y las letras en la España del siglo XVIII (2002) liburuan eman du, behinik behin (transkripzioa bera da bietan). Begiratu xehetasunak bibliografian.

${ }^{8}$ Ondoren grafia eta hizkera-ezaugarriren bat eguneratuta eman zuen testua, eta horrek eragin bide zion nahastea. 
Euskal testuari dagokionez, kanta hona transkribatzean, ez dugu grafiarik aldatu (ikusiko dugunez, grafia da testuaren berezigarri nabarmenenetako bat) eta azentuak zeuden-zeudenean utzi ditugu, testuan duten funtzioa argi izan ez arren (cf. $\$ 4$.2.1.3). Hitzen banaketa (funtsean, bi kasutan loturik ageri ziren elementuak bereizi ditugu: ilsirian 'hil ziren' eta nibeguira), letra larrien erabilera (hasierakoak batez ere) eta puntuazioa eguneratu ditugu, eta «Mar.» laburdura $\rightarrow$ «Marichu» garatu dugu. Bestalde, jatorrizkoan bigarren lerroan solte ageri zen «ibairá» lehenengo lerroaren amaierara eraman dugu, eta hurrengo orrialderako deia ezabatu. Zenbaketa dela eta, < > artean adierazitako zenbakia 1783ko edizioaren orrialde-zenbakiari dagokio; halakorik gabe ageri den zenbakia, aldiz, lerroen zenbaketari.

Hona hemen testua:

\section{ESCENA II}

Barreina se lebanta enternecido, coje el libro en que antes leia y se va adentro. Guitia mira con atención a Catalin, que suspira, se enjuga los ojos y buelbe a su labor: Marichu canta lo siguiente y se va con la ropa que tiene planchada:

$\begin{array}{lll}\text { Marichu canta: } & \text { Y lailá y lailá, acsohac gustiac ibairá } & 1 \\ & \text { Acsó, acsó, acsó, acsó, acsó, } & \\ & \text { Il sirian saspi acsó, aec sulora, ni beguira } & <8> \\ & \text { Acsoric empará se dila... (vase). } & \end{array}$

\section{Iruzkina}

\subsection{Kantaz}

Kanta labur horrek helburu zehatza du antzerki-lanaren osotasunean: obraren espazioa kokatzeko balio du, eta errealismoa ematen dio egileak bilatzen duen giro euskaldunari:

Que una comedia alojara un fragmento musical no era en principio especial novedad, pues la comedia barroca los había introducido a centenares. Lo era más en la práctica de la comedia neoclásica y el primer teatro sentimental, porque en ellos no aparecen estas muestras líricas. ¿Por qué, pues, lo hace y además en euskera? A mi entender, para dar frescura y verosimilitud al retrato de las costumbres que pinta, y de paso también para contribuir, al igual que lo había hecho el conde de Peñaflorida, a dignificar literariamente «el antiguo suave Bascuence»». (Urzainqui 2006: LIV-LV)

Kantari agertzen den pertsonaiaren izena ere ez da edozein, ezpada "Maritxu», euskal herri-literaturako konposizioetan sarri agertzen den izena.

Barnetxearen kanta edo kantaren zati bat ez da guztiz ezezaguna: gaur egunera arte iritsi zaizkigu aldaerak, eta Azkuek kanta bakotarren artean sailkatu zuen aldaera horietako bat bere kantutegian. ${ }^{9}$ Konposizio umoretsua da, non atsoak baitira irri-gai

\footnotetext{
9 Venancio Ameztiri jaso zion Zarautzen: «Atzo, atzo, atzo atzo il ziran amaŕ atso; baldin aŕdoa merkatzén ezpada, ilko dirade beste asko; atzo, atzo, atzo, atzo il ziran amaŕ atso". Beste ohar bat ere badakar: «Suelen repetir la canción con todas las palabras excepto una, la paitááa (aguardiente); en vez de baldin ardoa merkatzen ezpada, suelen decir: baldin paitáa merkatzen ezpada» (Azkue 1991 [1923]: 21). Gaur egunera arte heldu diren beste aldaera batzuetan, ardoaren edo pattarraren ordez, txokolatea aipatzen da.
} 
eta "galdu» edo «kondenatu», barre egiten dienaren aurrean. Hasierako hitz apaingarriek melodia irudikatu eta kanta hasiko dela iradokitzen dute, eta atzoren eta atsoren arteko hitz-jokoak eta umoreak goitik behera josten du testua.

\subsection{Hizkuntzaz}

4.2.1. Testuak ez du berezitasun edo arazo paleografikorik, baina grafiaren zein hizkuntzaren aldetik bi puntuk arreta ematen dute berehala: alde batetik, aipatzekoa da $<$ cs $>$ digrafoaren erabilera sistematikoa txistukari afrikatuetan; beste alde batetik, testua XVIII. mendearen amaierakoa dela aintzat hartuta, harrigarria da zenbat ezaugarri arkaiko duen.

4.2.1.1. Txistukarien sailean, frikariak eta afrikatuak grafikoki bereizten dira: <s> grafema ageri da frikari bizkarkariaren eta apikariaren lekuan, sistematikotasunez (1 gustiac; 3 ilsirian, saspi, sulora; 4 se); bestalde, esan bezala, afrikatu guztiak <cs> digrafoaren bidez ematen dira (1 acsohac 'atsoak', 2 acsó 'atzo' —bost aldiz—, 3 acsó 'atso', 4 acsoric 'atsorik'). Testuinguru bakar batean agertzen da txistukaria kontsonante ozenaren ondoren: aditz nagusiaren eta laguntzailearen artean (il sirian). Banaketa grafikoaz esandakoak aintzat hartuta, txistukari hori frikari ahoskatzen zela dirudi, Bizkai aldean gaur egun legez.

Ezagun da Larramendi baino lehen Hego Euskal Herriko testuetan, oro har, frikariak eta afrikatuak ez zirela grafikoki bereizten, eta gehienetan grafema bakunaren bidez ematen zirela; Xvi. eta XVII. mendeetako testu zahar batzuetan, ordea, aurki daitezke bestelako grafiak (inoiz oso bitxiak); hain zuzen ere, halakoak gogorarazten dizkigu Barnetxearen kantako <cs>-ak: digrafo berori edo antzekoak aurki daitezke Refranes y Sentencias bilduman, Zumarragaren gutunean eta Kapanagaren hitzaurrean, esate baterako. Halere, ez dira sistematikoak, ezpada salbuespenak: Refranes y Sentenciasen $<\mathrm{s}(\mathrm{s})>$ da nagusi, baina $<\mathrm{xs}>,<\mathrm{csh}\rangle,<\mathrm{cshsz}\rangle,<\mathrm{ts}\rangle$, $<$ sh $>$ eta $<$ shs $>$ ere badaude (Lakarra 1996: 23); Zumarragaren gutunean ere behin ageri da $<\mathrm{cs}>$ ozen ondoren ${ }^{10}$ eta birritan $<$ çz $>$ hitz amaieran (Padilla, Ulibarri \& Urgell prestatzen); Kapanagarenean, hitzaurrean bertan, ecsean eta ecsagunçaac bezalakoekin batera, digraforik gabeko formak ere badaude (Lakarra 1996: 18). Araban, Landuccik baditu "estrecho mar - içsasso estua» edo "guardador de cabras aunçsaya» bezalakoak, baina hiztegian <sç> da ordena arrunta, ez <çs> (Mitxelena 1958: 311).

Barnetxearenera itzulita, grafiak zenbait kontu iradokitzen dizkigu. Alde batetik, testuaren laburtasuna laburtasun, frikarien eta afrikatuen arteko bereizketa sistematikoak sistema grafikoaren modernotasuna islatzen du; hots, bereizketa grafikoa ondo egokitzen zaio Barnetxearen garaiari. Bestalde, <cs $>$ digrafoa ez da hain ohikoa izan

10 Ez dugu argi, ordea, frikaria ala afrikatua adierazten duen. xvi. mendeko mendebaleko beste testu batzuetan itxuraz ozen ondoren frikaria dago (Landucciren A eskuak hala eman zuela dirudi, esaterako; ik. Mitxelena 1958: 212), baina kasu honetan ez genuke baztertu beharko <cz> horrek afrikatua islatzea. Bihotz hitzak <çz> du hitz amaieran Zumarragarenean, eta ez dago halako digraforik frikari garbi direnak adierazteko; halere, digrafo horiek salbuespen dira testuan, oro har $<\mathrm{s}>-\mathrm{k}$ hala frikaria nola afrikatua adierazten duelako (esango, deuscuela; deusudaz, eseori). 
euskal tradizioan eta ez dugu oso argi zergatik edo non ikasita baliatu zuen bilbotarrak. Amaiera aldera itzuliko gara puntu honetara.

Frikariak eta afrikatuak adierazteko grafema eta digrafo berbera erabiltzeak Euskal Herriko mendebaleko testuetan agertu ohi den arazoa dakar Barnetxearen kantara ere: kontu grafiko hutsa izan daiteke, baina testua Bizkai aldekoa eta XVIII. mendearen amaierakoa izanda, pentsa daiteke, halaber, grafia bakar horrek txistukarien neutralizazioa islatzen duela, apikariaren alde frikarietan eta bizkarkariaren alde afrikatuetan, gaur egun bezala; hala balitz, $<\mathrm{cs}>-\mathrm{k}$ bizkarkaria adieraziko luke.

4.2.1.2. Grafiarekin jarraituz, Mitxelenak RSko hatxeez ari zela esan bezala, ${ }^{11}$ Barnetxearen testuko 1 acsohac horren <h>-a grafikoa besterik ez da. Ez du hasperenik adierazten, ezpada hiatoa, Euskara Arkaikoko eta Zaharreko beste testu batzuetan bezala; cf., esate baterako, RSko 220 parrahua -baina 419 perrau - 360 quehea eta 364 queheac —baina 473 eta 507 quea_, 372 hahoaz; 1619an Sevillan argitaratutako bertsoetako 55 armahaq —-baina 77 armaaq —; Viva Jesuseko 3 ahoan, 3 oherean, 3 ohera, 11 ardahoa, 14 destierruheu eta Kapanagaren hitzaurreko armahac.

4.2.1.3. Testuko hainbat hitzetan ezarri zuen azentu grafikoa Barnetxeak. Zehazki, testuko azentu markatu guztiak hitz amaierako bokaletan daude, baina bokalez amaitzen diren hitz guztietan ez dago azentu markaturik: 1 lailá — bitan-, 3 saspi, 1 ibairá, 4 empará - baina 3 sulora, 3 ni beguira, 4 dila-. Aurretik aipatutako acsó ('atso' zein 'atzo') horietan sistematikoa da tileta <o>-ren gainean, hitzari bestelako morfema bat gehitzen zaionean izan ezik: 1 acsohac, 4 acsoric.

Ez dakigu azentu grafiko horiek guztiek testua idatzi zen sasoiko azentuazioa islatzen duten, kantaren melodia edo erritmoa markatzen duten, apaingarri hutsak diren ala azalbide horietatik guztietatik zerbait dagoen. Esate baterako, 1 lailáko azentu grafikoak lotura izan dezake erritmoarekin, eta 1 ibairák ere azentua leku berean markatua izatea lagungarri da errimarako. Bestalde, bigarren bertso-lerroko acsó guztiek azentu markatua izateak eta bestelako morfemaren bat gehitzean azentua desagertzeak adieraz lezake acsó horietan sasoiko azentua azken bokalean zegoela. Nolanahi ere den, ziurgabetasun gehiegi dira azentuazio-arau argirik lortzeko.

4.2.1.4. Izenaren morfologian, aec 'haiek' zaharra agertzen da, Arabako, Bizkaiko eta Gipuzkoako testu zaharretan eta zenbait klasikotan bezala (OEH s.v. haiek).

4.2.1.5. Aditzari dagokionez, aipagarria da $-t u /-\varnothing$ oposizioan aditzoinari eutsi izana 4 empará se dila adibidean, aintzat harturik xvi. mendeaz geroztik oposizioa lehenengoaren alde galtzen hasia zela mendebalean (nahiz eta ez era batera leku guztietan) eta hizpide dugun testua XVIII. mendearen amaieran inprimatu zela. Izanen laguntzaileak mendebal zabaleko disimilazioa du, ${ }^{12}$ non $-e a>-i a$ bihurtu baita: $3 \mathrm{Il}$

11 «En puridad, el problema se reduce a las hh iniciales, ya que en interior de palabra, caso no muy frecuente en esta colección de proverbios, $h$ sirve más que nada para señalar hiatos, al menos gráficos, o en algún caso límites de morfema» (1979: 162).

${ }^{12} \mathrm{Ez}$ da mendebal zabal horretako testu guztietan agertzen: Araban, esate baterako, Landuccik ez dakar halakorik (Mitxelena 1961b: 94). 
sirian 'hil ziren'. Bestalde, bizkaiera zaharreko ohiko asimilazioa dago *edinen adizkian: 4 empará se dila.

4.2.1.6. Sintaxian, ez partikula aditz nagusiaren eta laguntzailearen artean ageri da, joskera zaharrari eutsiz (Lakarra 1986: 655): 4 empará se dila.

4.2.1.7. Testuak, bere laburtasunean, ez du berezitasun lexiko handirik: se 'ez' aldaera aipa daiteke, ohikoa Bizkaiko testu zaharretan. Bestalde, empará aditzaren esanahia 'salbatu', 'libratu', 'babestu'-tik hurbil dago. Tradizio idatzian esanahi horien adibide gehienak Ipar Euskal Herrikoak diren arren, Bizkaiko eta Arabako testu zaharretan ere ageri dira; adibidez, Arrasateko erreketaren kantetako çeuren Jauna ezçencan enpara (Arriolabengoa 2008: 87) edo Mendietak jasotako Abendañoren aieneko Oi aldioneri albanegui empara (Mitxelena 1964: 78) aipa daitezke.

4.2.2. Aurreko guztiak aintzat hartuta, agerikoa da Barnetxearen antzerki-laneko kanta bitxia eta berezia dela. Alde batetik, egilearen garaiarekin bat egiten duten ezaugarriak ditu: txistukari frikarien eta afrikatuen sailak grafikoki bereizten dira (ez dugu erabat ziur esaterik, baina sail bakoitzean grafia bakar bat erabiltzeak neutralizazioa ere isla dezake), eta $-e a>-i a$ bihurtu da, XVIII. mendearen hasieraz/erdialdeaz geroztiko Bizkaiko hainbat testutan legetxe. Beste alde batetik, forma zahar batzuk gutxienez 150-200 urte lehenagoko hizkerari dagozkio, oro har, XVIII. mendearen azken hamarkadako euskarari baino gehiago: -tul-ø-ren artean aditzoina erabiltzea, aec eta se aldaerak, azken horren sintaxia eta enparatu 'salbatu', kasurako. Izatez, arkaismoak agertzea baino gehiago, arkaismo horiek guztiak testu hain laburrean aldi berean agertzea da deigarri.

Kantak, otoitzak eta herri-literaturako bestelako formulak buruz ikasten zirela gogoan izanda, ohikoa izaten da halako materialetan aurreko garaietako formak fosildurik gordetzea. Horrek azal lezake, jakina, kantaren kutsu zaharra: esate baterako, Lakarra (1986: 665)-ri jarraikiz, -tul-ø-ren artean forma partizipiodunak nagusi ziren jada XVII. mendeko testuetan, eta oposizioa galdua zen partizipiodunen alde XVIII. mendeko prosa-lanetan; baina, Bertso bizkaitarrak sortan (1688) eta Barrutiaren Acto para la nochebuenan (xviII. mendearen hasiera) forma zaharrak gordetzen ziren oraindik. Barnetxeari dagokionez, aintzat hartu behar da, halere, a) hainbat direla, testuaren laburtasunean, ezaugarri zaharrak; b) bilbotarrarena bi testu horiek baino (ia) mende bat geroago argitaratu zela.

Horiek guztiak aintzat hartuta, ez da erraza Barnetxeak emandako kantaren jatorria zehaztea. Alde batetik, arkaismoek kutsu zahar nabarmena ematen diote testuari, ezohikoa XVIII. mendearen amaieran; ${ }^{13}$ ez dakigu kanta arkaismo horiek guztiak gordetzen zituen hizkera batekoa den ala arkaismo horiek guztiak kantan fosildurik gorde ziren XviII. mendera arte. Bestalde, txistukari frikariak eta afrikatuak bereizteko ohitura modernoa da Hego Euskal Herrian (xviII. mendearen erdialdeaz geroztikoa, oro har, zenbait egileren -Madariaga, Garibai, etab.— proposamen antzuak proposamen), eta -ea > -ia bilakabidea ere XVIII. mendearen lehenengo hamarkadetan

\footnotetext{
13 Nolanahi ere den, Ulibarrik (2015) Arabako ipar-mendebalean kokatu duen Dotrinazko sermoitegiak erakusten du ezohikoa ez dela ezinezko; izan ere, editatu eta aztertu dituen sermoietan hainbat eta hainbat arkaismo esanguratsu eta harrigarri daude, nahiz eta XvIII. mendearen amaierakoak izan.
} 
ugaritzen da mendebaleko testuetan (bi ezaugarri horiek ondo ezkontzen dira, beraz, testua argitaratu zen sasoiarekin). Arkaismoen eta joera berrien arteko nahaste hori gutxi balitz bezala, <cs> grafia ere ez da arruntena ez xviı. mendeko, ez lehenagoko euskal testuetan, nahiz eta bilbotarrarenean sistematikoa izan txistukari afrikatuak adierazteko.

Txistukarien sailak bereizi izanak islatzen du Barnetxeak, zuzenean edo zeharka (hots, beste norbaiten laguntzarekin), izan zuela mendearen erdialdeko joera berrien berri, eta beharbada bilbotarrak izan zezakeen «laguntzaile» edo «aholkulari» baten bidez azal daiteke <cs $>$ grafiaren erabilera ere, nahiz eta Larramendik $<$ tz $>$ eta $<$ ts $>$ proposatuak zituen afrikatuak adierazteko (Lakarra 1985a: 244): ${ }^{14}$ sinesgarri dirudi proposatzea Barnetxeak inoren laguntza izan zuela. Ikusitakoak ikusita, ustezko laguntzaile-aholkulari hark orduko euskal letra-jendearen proposamenen jakitun izan behar zuen, eta, Barnetxearen harreman-sarea zein zen gogoan izanda, ez genuke Adiskideen Elkartearen ingurutik urrunegi bilatu beharko. ${ }^{15}$

4.2.3. Bi hitz testuaren hizkeraren kokapen geografikoaz: ez dirudi arazorik dagoenik testua Bizkai aldean kokatzeko, baina ez du zertan Bilbo ingurukoa izan, nahiz eta Barnetxea han jaio zen eta antzezlanaren espazioa Portugalete ingurua den. Hizkuntza-ezaugarriak hartuta, Lakarra (1985b: 289)-ren arabera, Mikoleta bilbotarrak, XVII. mendearen erdialdean, bospasei adibidetan du - $\emptyset$ eta hamar-hamaikatan -tu. Bestalde, guzti baliatu zuen Barnetxeak, ez Bilbo aldean testu zaharretan nahiz gaur egun ageri den $d u z t i .^{16}$

\section{Bibliografia}

Altzibar, X. (arg.), 1991, Gabonsariak. El Borracho burlado. Xabier de Munibe, Conde de Peñaflorida (edizio kritikoa), Vitoria-Gasteiz: Eusko Legebiltzarra.

Arriolabengoa, J., 2008, Euskara Ibarguen-Cachopin kronikan, Bilbo: Euskaltzaindia \& BBK Fundazioa.

Azkue, R.M., 1991 [1923], Cancionero popular vasco, Bilbo: Euskaltzaindia.

—, 1989 [1945], Euskaleriaren yakintza III. Proverbios, modismos, lenguaje infantil, trabalenguas, sobrenombres, aciertos, Madril \& Bilbo: Euskaltzaindia \& Espasa Calpe.

García Garrosa, M.J., 2005, «En los inicios de la comedia neoclásica: «La aya, de María Rita de Barrenechea (1750-1795). Estudio y edición», Cuadernos de Estudios del siglo XVIII $14,25-66$.

14 Kardaberatzek Eusqueraren berri onac (1761) lanean Larramendiren $<$ tz $>$ eta $<$ ts $>$ gomendatu zituen arren, ez zuen $<\mathrm{tz}>$ sistematikoki erabili. Begiratu hernaniarraren eta XVIII. mendeko beste egile batzuen grafia-ohiturak Lakarra (1985a) lanean.

15 Badaezpada, Peńafloridaren euskal testuak begiratu ditugu, baina ez dugu Barnetxeak baliaturiko grafien antzekorik aurkitu.

16 Aldaera lexikoaren argudio hori ez da, dena den, erabakigarri: testu zaharretan Mikoletak $d$ - besterik ez du, baina lehenagoko eta inguru bertsuko $R S$ bilduman bietarik dago: 123 guztietan, 135 guztiz, 316 guztioc... zein 96 \& 245 duztioc, 259 duztia eta 387 dustien. Cf. orobat Azkuek Euskalerriaren Yakintzaren hirugarren liburukian jasotako 1530 Barakaldoko kerizäa duztia da mantekäa esaera (1989 [1945]: 141). Egungo hizkeretan ere, Bilbotik itsasora bitarteko herrietan eta Txorierriko zenbaitetan darabilte $d$-, baina Bilbotik hegoaldera $g$ - besterik ez dago. 
Knörr, H., 2005, «Emilio Palacios, 2000». [La mujer y las letras en la España del siglo XVIII lanaren iruzkina], Landazuri 11-12-13 (2005), 71-72.

Lakarra, J.A., 1985a, "Literatur gipuzkerarantz: Larramendiren Azkoitiko sermoia», ASJU 19:1, 235-281.

—, 1985b, «-tul-ø bizkaiera zaharrean», Litterae vasconicae 3, 281-292.

—, 1986, «Bizkaiera zaharra euskalkien artean», ASJU 20:3, 639-682.

-, 1996, Refranes y sentencias. Ikerketak eta edizioa, Bilbo: Euskaltzaindia.

Mitxelena, K., 1958, "Introducción al Dictionarium Linguae Cantabricae» berrarg. in OC XII, 202-232.

—, 1961a, "Judíos de Guevara y vascos de Oñate», berrarg. in OC XI, 53-65.

—, 1961b, Fonética histórica vasca, berrarg. in OC VI.

—, 1964, Textos arcaicos vascos, berrarg. in OC XII, 1-197.

—, 1979, "La letra $h$ en los Refranes y sentencias de 1596», berrarg. in OC XI, 159-167.

- \& Agud, M. (arg.), 1958, N. Landuchio. Dictionarium Linguae Cantabricae (1562), berrarg. in $O C X I I, 209-388$.

— \& Sarasola, I., 1987-2005, Orotariko Euskal Hiztegia, Bilbo: Euskaltzaindia.

Padilla, M., Ulibarri, K. \& Urgell, B. (prestatzen), Krestomatia. Euskara Arkaikoa eta Zaharra ezagutzeko 50 testu.

Palacios Fernández, E., 2000, «Noticia sobre el parnaso dramático femenino en el siglo XVIII", in García Lorenzo, L. (arg.), Autoras y actrices en la historia del teatro español, Murtzia: Universidad de Murcia.

—, 2002, La mujer y las letras en la España del siglo XVIII, Madril: Ediciones Laberinto.

Towsend, J., 1988, Viaje por España en la época de Carlos III (1786-1787), Madril: Turner.

Ulibarri, K., 2015, Dotrinazko sermoitegia: galduriko hizkerak eta dialektologia historikoa, Vitoria-Gasteiz: UPV/EHUko doktore-tesi argitaragabea. Zuz.: Blanca Urgell.

Urzainqui, I. (arg.), 2006, "Catalin» de Rita de Barrenechea y otras voces de mujeres en el siglo XVIII, Vitoria-Gasteiz: Arartekoa.

\author{
Eneko Zuloaga \\ UPV/EHU \\ Hizkuntzaren eta Literaturaren Didaktika Saila \\ Hezkuntza Fakultatea \\ Sarriena auzoa, z/g. 48940 Leioa (Bizkaia) \\ 946014647 \\ eneko.zuloaga@ehu.eus
}




\section{Eranskinak}

\section{B \\ CATADT. \\ COMEDIA EN PROSA. \\ Bs la Comedia espejo de la vida, \\ su fin mostrar los vicios, y virtudes \\ para vivir con òrden, $y$ medida. \\ ANDRES REY DE ARTIEDA. Epist.

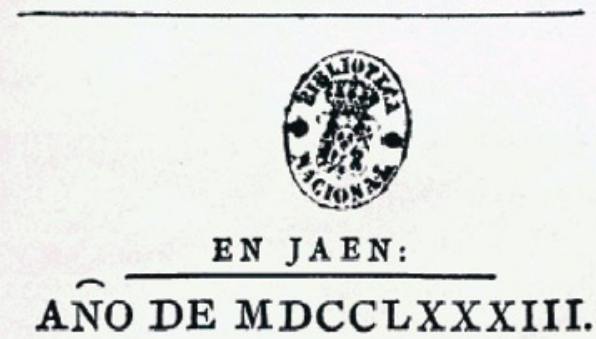

1. irudia

Catalin antzerki-lanaren azala 


\section{(8)}

Barr. Hija mia : $\mathrm{Si}$ tu suspiras....

Guit. y Cat. Qué ? Señor.

Barr. Nada , Hijos mios. ¡Há pobre Catalin!

\section{ESCENA}

Barreina se lebanta enternecido: coje el libro, en que antes leia, y se vá adentro: Guitia mira con atencion á Catalin, que suspira, se enjuga los ojos, y buelbe à su labor: Marichú canta lo siguiente, y se vá con la ropa, que tiene planchada.

Mor. Canta. Y lailá, y lailá acsohac gustiac ibairá.

Acsó, acso , acsó, acsó, acsó,

Ilsirian saspí acsó , aec sulora nibeguira, acso-

\section{2. irudia}

Kantaren lehenengo zatia 


\section{(9)}

acsoric empará se dila.. (vase)

Guit. aparte) †Pobre Catalin ! ¿Y porqué ? Qué la habrá sucedido? No; yo no puedo vivir en esta cruel incertidumbre : (despues de haver discurrido un rato. ) ¿Porqqué trabaja Vm. tanto, Señora Catalin? Cat. Es preciso.

Guit. Asi pudiera yo ayudar á Vm. para no verla tan atareada.

Catalin le mira tiernamente, $y$ buelbe à baxar los ojos.

Cat. Lo agradezco.

Guit. Vaya, lebante Vm. esos ojos; es buen modo de cumplir la palabra ; yá no es hora de coser mas. (la quita la labor.)

Cat.

\section{3. irudia}

Kantaren azken zatia 